\title{
Accuracy of medical models made by consumer-grade fused deposition modelling printers
}

\author{
Christian Petropolis MD, Daniel Kozan MD, Leif Sigurdson MD MSc MBA FRCSC
}

\begin{abstract}
C Petropolis, D Kozan, L Sigurdson. Accuracy of medical models made by consumer-grade fused deposition modelling printers. Plast Surg 2015;23(2):91-94.
\end{abstract}

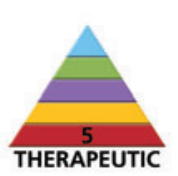

BACKGROUND: Additive manufacturing using fused deposition modelling (FDM) has become widely available with the development of consumergrade three-dimensional printers. To be useful in maxillofacial surgery, models created by these printers must accurately reproduce the craniofacial skeleton.

OBJECTIVE: To determine the accuracy of consumer-grade FDM printers in the production of medical models compared with industrial selective laser sintering (SLS) printers.

METHODS: Computed tomography images of a dry skull were manipulated using OsiriX (OsiriX, Switzerland) and ZBrush (Pixologic, USA) software. Models were fabricated using a consumer-grade FDM printer at $100 \mu \mathrm{m}, 250 \mu \mathrm{m}$ and $500 \mu \mathrm{m}$ layer heights and an industrial SLS printer. Seven linear measurements were made on the models and compared with the corresponding dry skull measurements using an electronic caliper. RESULTS: A dimensional error of $0.30 \%$ was observed for the SLS models and $0.44 \%, 0.52 \%$ and $1.1 \%$ for the $100 \mu \mathrm{m}, 250 \mu \mathrm{m}$ and $500 \mu \mathrm{m}$ FDM models, respectively.

CONCLUSION: Consumer-grade FDM printers can produce medical models with sufficient dimensional accuracy for use in maxillofacial surgery. With this technology, surgeons can independently produce low-cost maxillofacial models in an office setting.

Key Words: Craniofacial; Precision; Preoperative models; Rapid prototyping

The production of medical models for maxillofacial surgery has typi1 cally employed complex, industrial printing technology such as selective laser sintering (SLS), three-dimensional (3D) printing and Polyjet (Stratasys Inc, USA) (1). Recently, consumer-grade fused deposition modelling (FDM) printers have become widely available at relatively low cost, making additive manufacturing more accessible to surgeons. Multiple printers employing an FDM process are currently available between $\$ 500$ and $\$ 4,000$. In contrast, industrial 3D printers typically used for production of medical models cost several times this amount (2). Consumer-grade FDM printers can be operated and maintained without advanced technical knowledge in an office setting.

FDM printers build parts layer on layer with thermoplastic material heated to a semiliquid state and extruded according to a computercontrolled path. Models are printed with z-axis (layer height) resolution between $50 \mu \mathrm{m}$ and $500 \mu \mathrm{m}$. Increasing the $z$-axis resolution of a model increases its production time. Polylactic acid (PLA) and acrylonitrile butadiene styrene (ABS) are the two thermoplastics most commonly used in FDM printing. PLA is a plant-based plastic, which is hard and brittle once extruded. ABS is more durable and flexible compared with PLA, but has a tendency to warp (3).

El-Katatny et al (4) previously examined the dimensional accuracy of an industrial FDM printer, comparing printed models with skull computed tomography (CT) data. The printer tested in the present study was an FDM 3000 (Stratasys Inc, Canada), which showed highly accurate reproduction when compared with CT data. The dimensional accuracy of consumer-grade FDM printers has not been previously

\section{La précision de modèles médicaux produits par des imprimantes pour consommation courante faisant appel à la modélisation par dépôt de fil en fusion}

HISTORIQUE : La fabrication additive faisant appel à la modélisation par dépôt de fil en fusion (FDM) s'est généralisée grâce au développement des imprimantes tridimensionnelles pour consommation courante. Pour être utiles en chirurgie maxillo-faciale, les modèles créés par ces imprimantes doivent reproduire le squelette craniofacial avec précision.

OBJECTIF : Déterminer la précision d'imprimantes FDM pour consommation courante dans la production de modèles médicaux par rapport à des imprimantes industrielles faisant appel au frittage sélectif par laser (SLS). MÉTHODOLOGIE : Les chercheurs ont manipulé les images tomodensitométriques d'un crâne séché à l'aide des logiciels OsiriX (OsiriX, Suisse) et ZBrush (Pixologic, États-Unis). Ils ont fabriqué les modèles à l'aide d'une imprimante FDM pour consommation courante, à des épaisseurs de couche de $100 \mu \mathrm{m}, 250 \mu \mathrm{m}$ et $500 \mu \mathrm{m}$, ainsi qu'à l'aide d'une imprimante SLS industrielle. Au moyen d'un pied à coulisse électronique, ils ont effectué sept mesures linéaires sur les modèles, qu'ils ont comparées aux mesures du crâne séché.

RÉSULTATS : Les chercheurs ont observé une erreur dimensionnelle de $0,30 \%$ dans les modèles SLS et de 0,44\%, 0,52 \% et 1,1\% dans les modèles FDM à $100 \mu \mathrm{m}, 250 \mu \mathrm{m}$ et $500 \mu \mathrm{m}$, respectivement.

CONCLUSION : Les imprimantes FDM pour consommation courante produisent des modèles médicaux de précision dimensionnelle suffisante pour être utilisés en chirurgie maxillo-faciale. Grâce à cette technologie, les chirurgiens peuvent produire eux-mêmes des modèles maxillo-faciaux à faible coût en cabinet.

reported. Without confirmation of accuracy, the utility of consumergrade $3 \mathrm{D}$ printers is questionable for medical model production.

The purpose of the present study was to evaluate the dimensional accuracy of maxillofacial models produced using a consumer-grade FDM printer compared with a dry human skull. By demonstrating the accuracy of this FDM process, we show that it is a viable method for surgeons to independently produce low-cost maxillofacial models in an office setting.

\section{METHODS}

A dry skull with plastic teeth was acquired from Osta International (White Rock, Canada). A positron emission tomography/CT (Biograph 16, Siemens, Germany) scan was used to obtain the CT data. Incremental $1 \mathrm{~mm}$ coronal slices were obtained. OsiriX 5.5.2 (OsiriX, Switzerland) was used to create a stereolithography (STL) file using the following parameters: resolution high, decimation off, smoothing off, threshold 0 Hounsfield units (HU).

ZBrush 4R6 (Pixologic, USA) software was used to crop all 3D models and to add support structures to the FDM midface model. All STL files were verified and repaired using netfabb basic 4.9.1 (netfabb $\mathrm{GmbH}$, Germany). FDM models were printed using a CubeX printer (3dSystems, USA) using PLA plastic. Printer settings were: rafts off, supports off, fine detail off, thin fill. Models were created with layer heights of $100 \mu \mathrm{m}, 250 \mu \mathrm{m}$ and $500 \mu \mathrm{m}$. No finishing was performed on the FDM midface models other than external support material removal. The FDM mandible models were printed in two pieces to eliminate the

Division of Plastic and Reconstructive Surgery, Department of Surgery, University of Manitoba, Winnipeg, Manitoba

Correspondence: Dr Christian Petropolis, Department of Surgery, University of Manitoba, GH604, 820 Sherbrook Street, Winnipeg,

Manitoba R3A 1R9. Telephone 204-898-8072,e-mail cpetropolis@icloud.com 


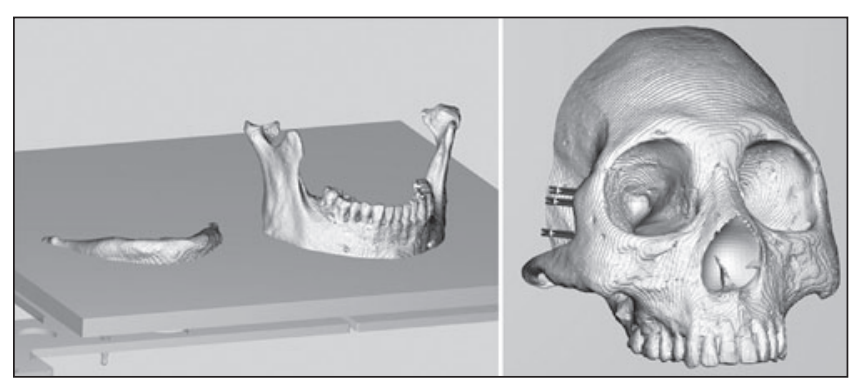

Figure 1) Stereolithography models used in the fused deposition modelling printing process. Midface model is shown with internal and external supports; mandible model with axial split

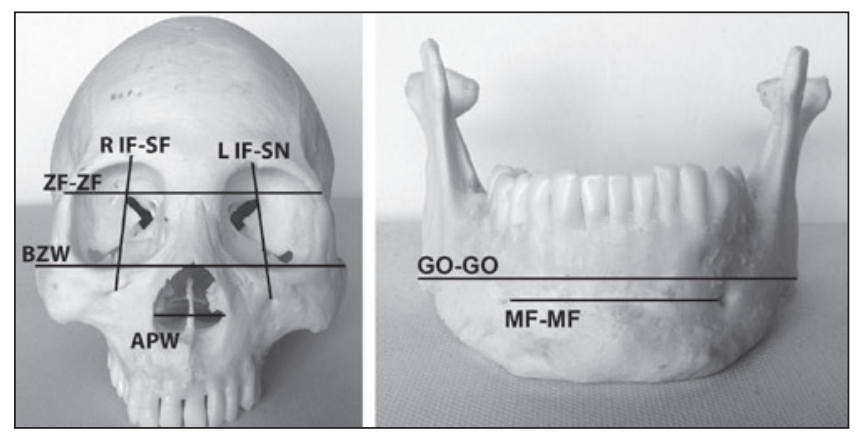

Figure 2) Linear measurements. APW Aperture piriformis width; BZW Bizygomatic width; GO-GO Distance between right and left gonion; L IF-SN Distance between left infraorbital foramen and supraorbital notch; MF-MF Distance between right and left mental foramen; $R$ IF-SF Distance between right infraorbital foramen and supraorbital foramen; ZF-ZF Distance between right and left zygomaticofrontal suture

need for support structures, and were assembled with cyanoacrylate glue (Figure 1). The approximate cost of each model pair was $\$ 20$.

An EOSINT P 395 printer (EOS GmbH, Germany) with nylon powder was used for the production of the SLS model. The SLS midface model was printed without support structures and the SLS mandible model was printed as one piece. No finishing was performed on the models. The cost of the model pair was approximately $\$ 250$.

Linear measurements (Figure 2 and Table 1) were made using an IP54 EZ Cal electronic caliper (iGaging, USA). The data were analyzed using descriptive statistics, and Student's $t$ test for paired samples. Dimensional error was calculated for each linear measurement as the absolute difference $(\mathrm{mm})$ between the values obtained from the dry skull and model. The percent relative differences were calculated as the absolute difference divided by the skull value multiplied by 100 . These methods were based on previous studies by Choi et al (5), Chang et al (6) and Silva et al (7). Measurements of the dry skull and models were performed 20 times for each data point by the same observer.

Mean absolute difference $(\mathrm{mm})=$ model value - dry skull value

Mean relative difference $(\%)=($ model value - dry skull value $) \times 100$ dry skull value

\section{RESULTS}

Figure 3 shows the linear measurements for the dry skull and models. For each linear measurement, there was a statistically significant difference (ie, $\mathrm{P} \leq 0.05$ ) between the dry skull and each of the models.

Figures 4 and 5 show the mean differences in linear measurements between the dry skull and models. These data were used to calculate the mean relative difference in all linear measurements. Mean errors were $0.16 \mathrm{~mm}(0.30 \%)$ for the SLS models, $0.21 \mathrm{~mm}(0.44 \%)$ for the $100 \mu \mathrm{m}$ FDM models, $0.24 \mathrm{~mm}(0.52 \%)$ for the $250 \mu \mathrm{m}$ FDM models
TABLE 1

Landmarks and linear measurements

\begin{tabular}{ll}
\hline Landmarks & Definition \\
\hline AP - aperture piriformis & $\begin{array}{c}\text { Point at the lateral margin of the AP } \\
\text { (bilateral) }\end{array}$ \\
ZF - zygomaticofrontal suture & $\begin{array}{c}\text { Point at the lateral margin of the } \\
\text { ZF (bilateral) }\end{array}$ \\
MF - mental foramen & Point at the medial margin of the MF \\
& (bilateral) \\
Go - Gonion & Point at the most lateral prominence of \\
& the mandibular angle (bilateral) \\
IF - infraorbital foramen & Point at the superior margin of the \\
SF - supraorbital foramen & IF (bilateral) \\
SN - supraorbital notch & Point at the inferior margin of the \\
& SF (right) \\
Zy - zygion & Point at the superior margin of the \\
\hline Measurements & SN (left) \\
\hline R IF-SF & Point at the most lateral prominence of \\
L IF-SN & the zygomatic arch (bilateral) \\
ZF-ZF &
\end{tabular}

and $0.56 \mathrm{~mm}(1.1 \%)$ for the $500 \mu \mathrm{m}$ FDM models. Printing times for the FDM models are summarized in Table 2.

\section{DISCUSSION}

Our study showed that a consumer-grade FDM printer can produce medical models with accuracy similar to an industrial SLS printer (mean errors of $0.44 \%$ and $0.30 \%$, respectively). El-Katatny et al (4) previously evaluated the accuracy of maxillofacial models produced on an industrial FDM printer (FDM3000; Stratasys Inc, Canada). In their study, linear measurements performed using a digital caliper were compared with skull CT data and showed a mean error of $0.24 \%$. The SLS control in our study had accuracy comparable with a recent study by Salmi et al (1). A summary of model accuracy from relevant studies is shown in Table 3.

The $100 \mu \mathrm{m}$ FDM and $250 \mu \mathrm{m}$ FDM models both had similar accuracy, while the $500 \mu \mathrm{m}$ FDM models had approximately double the mean error $(0.44 \%, 0.52 \%$ and $1.1 \%$ respectively). Figure 6 shows a comparison of the midface models at each resolution. Replication of thin bone in the FMD process was limited by the extruder nozzle diameter of $0.5 \mathrm{~mm}$. This was reflected in the aperture piriformis width, which had the greatest error of all the measurements in the FDM models. Increasing the $z$-axis resolution from $250 \mu \mathrm{m}$ to $100 \mu \mathrm{m}$ provided little benefit to dimensional accuracy. At higher resolutions $(>250 \mu \mathrm{m})$, the limiting factor in model accuracy increasingly becomes the CT data processing rather than the FDM process. The FDM process at $500 \mu \mathrm{m}$ resolution is unable to reproduce the finer structures found in craniofacial models and, therefore, we recommend a resolution of $\geq 250 \mu \mathrm{m}$.

Acquisition and processing of the CT data can have a significant effect on model accuracy. The threshold of $0 \mathrm{HU}$ used in STL creation was at a density level below that of cortical osseous tissue, but was required to capture an accurate $3 \mathrm{D}$ reconstruction. Any operations or conversion made to the CT data will result in loss of information (8). In our study, STL files were created at the highest resolution possible without smoothing or decimation. Generalized smoothing was not performed because it obscured fine details in the bony landmarks. Decimation of an STL file is used to control the 


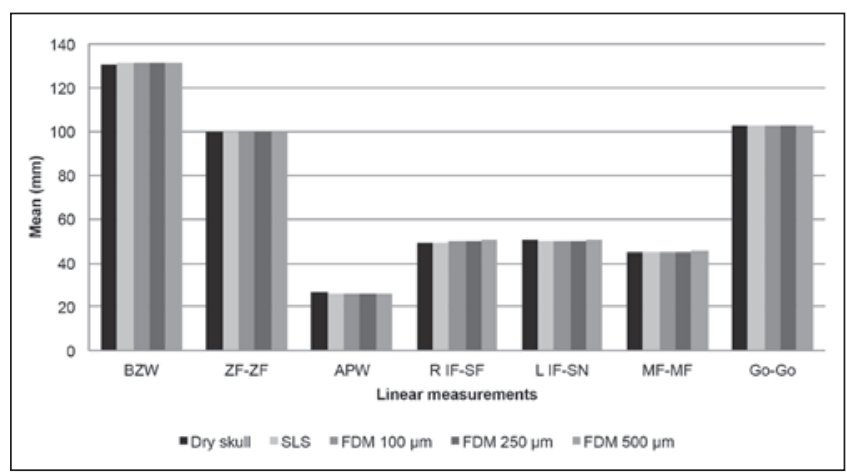

Figure 3) Mean \pm SD of the dry skull, selective laser sintering (SLS), fused deposition modelling (FDM) $100 \mu \mathrm{m}$, FDM $250 \mu \mathrm{m}$ and FDM $500 \mu \mathrm{m}$ models. Dry skull: Bizygomatic width $(B Z W)=130.97 \pm 0.024$; distance between right and left zygomaticofrontal suture $(\mathrm{ZF}-\mathrm{ZF})=99.62 \pm 0.11$; aperture piriformis width $(A P W)=26.50 \pm 0.065$; distance between right infraorbital foramen and supraorbital foramen $(R I F-S F)=49.12 \pm 0.24$; Distance between left infraorbital foramen and supraorbital notch (L IF-SN) $=50.18 \pm 0.080$; distance between right and left mental foramen (MF$\mathrm{MF})=44.56 \pm 0.024$; Distance between right and left gonion $\left(\mathrm{Go}_{0}-\mathrm{Go}_{0}\right)=$ 102.66 \pm 0.026 . SLS: $B Z W=131.13 \pm 0.028 ; Z F-Z F=99.78 \pm 0.074$; $A P W=26.39 \pm 0.10 ; R I F-S F=49.28 \pm 0.12 ; L I F-S N=49.81 \pm 0.10$; MF-MF $=44.71 \pm 0.016 ;$ Go-Go $=102.70 \pm 0.031$. FDM $100 \mu \mathrm{m}:$ $B Z W=131.19 \pm 0.023 ; Z F-Z F=99.54 \pm 0.071 ; A P W=26.23 \pm 0.059$; $R$ IF-SF $=49.53 \pm 0.052 ;$ L IF-SN $=49.89 \pm 0.039 ; M F-M F=44.71 \pm$ 0.025; Go-Go = 102.70 \pm 0.079 ). FDM $250 \mu \mathrm{m}: \mathrm{BZW}=131.05 \pm 0.048$; $Z F-Z F=99.83 \pm 0.066 ; A P W=26.10 \pm 0.058 ; R I F-S F=49.49 \pm 0.069 ; \mathrm{L}$ IF-SN $=49.84 \pm 0.084 ; \mathrm{MF}-\mathrm{MF}=44.66 \pm 0.015 ; \mathrm{Go}-\mathrm{Go}=102.47 \pm 0.032$. FDM $500 \mu \mathrm{m}: B Z W=131.64 \pm 0.059 ; Z F-Z F=100.12 \pm 0.065 ; A P W$ $=25.80 \pm 0.056 ; R$ IF-SF $=50.18 \pm 0.093 ; \mathrm{L}$ IF-SN $=50.36 \pm 0.091$; $\mathrm{MF}-\mathrm{MF}=45.22 \pm 0.065 ;$ Go-Go $=102.82 \pm 0.054$

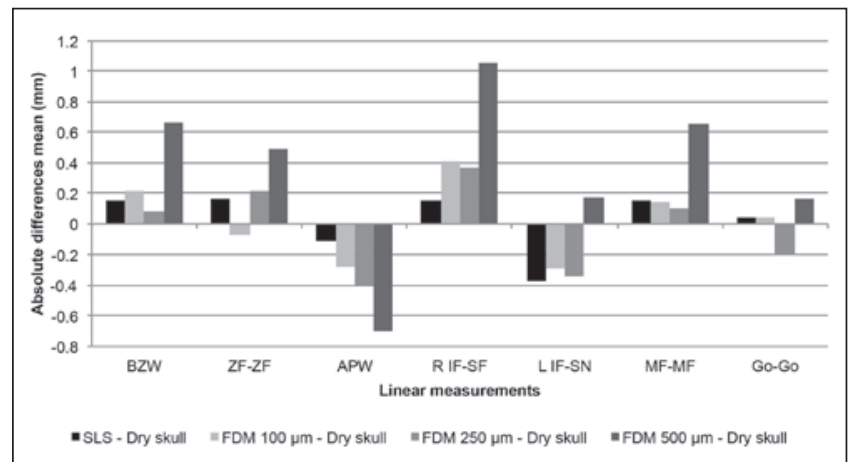

Figure 4) Comparison of linear measurements of dry skull, selective laser sintering (SLS), fused deposition modelling (FDM) $100 \mu \mathrm{m}$, FDM $250 \mu \mathrm{m}$ and FDM 500 um models: absolute difference in mean values. APW Aperture piriformis width; BZW Bizygomatic width; Go-Go Distance between right and left gonion; L IF-SN Distance between left infraorbital foramen and supraorbital notch; MF-MF Distance between right and left mental foramen; $R$ IF-SF Distance between right infraorbital foramen and supraorbital foramen; ZF-ZF Distance between right and left zygomaticofrontal suture

data size of a model by reducing its polygon count and, thus, accuracy. In practice, we avoid decimation unless the model data size interferes with subsequent steps in production.

ABS and PLA are the predominant plastics used in FDM printers. Both plastics are gas sterilizable and sufficiently rigid to serve as a template for plate bending $(9,10)$. Compared with ABS, PLA is less flexible with a lower melting temperature, and undergoes hydrolysis when exposed to water (9). Protection from excess heat and humidity is, therefore, required to prevent distortion of PLA models. ABS is prone to warping during the FDM printing process, which can result in inaccurate models or print failure if the model becomes detached from the print bed. The risk of ABS

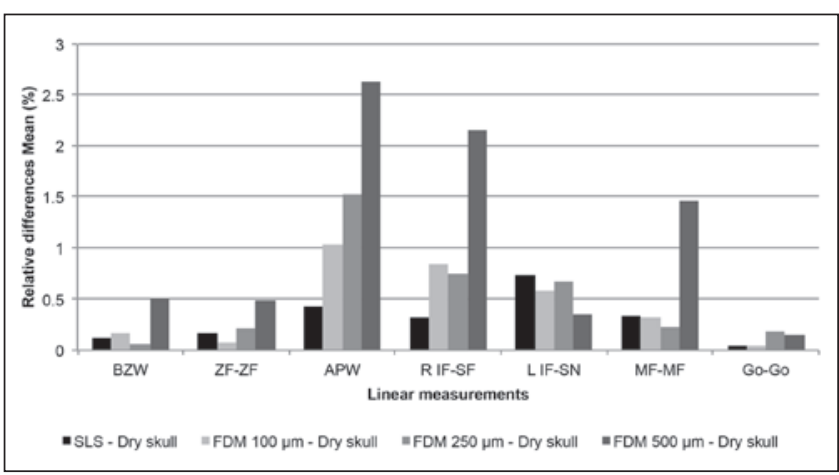

Figure 5) Comparison of linear measurements of dry skull, selective laser sintering (SLS), fused deposition modelling (FDM) FDM $100 \mu \mathrm{m}$, FDM $250 \mu \mathrm{m}$ and FDM $500 \mu \mathrm{m}$ models: relative difference in mean values. BZW Bizygomatic width; Go-Go Distance between right and left gonion; L IF-SN Distance between left infraorbital foramen and supraorbital notch; MF-MF Distance between right and left mental foramen; $R$ IF-SF Distance between right infraorbital foramen and supraorbital foramen; ZF-ZF Distance between right and left zygomaticofrontal suture

TABLE 2

Print times of fused deposition modelling models

\begin{tabular}{ll}
\hline Mandible model & Print time, min \\
\hline $100 \mu \mathrm{m}$ & 549 \\
$250 \mu \mathrm{m}$ & 330 \\
$500 \mu \mathrm{m}$ & 125 \\
\hline Midface model & \\
\hline $100 \mu \mathrm{m}$ & 1241 \\
$250 \mu \mathrm{m}$ & 757 \\
$500 \mu \mathrm{m}$ & 321 \\
\hline
\end{tabular}

\section{TABLE 3}

Comparison of studies with additive manufacturing accuracy measurements

\begin{tabular}{|c|c|c|}
\hline Author (ref) & Comparison & Mean difference, $\%$ \\
\hline \multirow[t]{3}{*}{ Present study } & FDM - dry skull & $0.44,0.52 \& 1.1$ \\
\hline & (100, 250 and $500 \mu \mathrm{m}$ models $)$ & \\
\hline & SLS - dry skull & 0.30 \\
\hline \multirow[t]{3}{*}{ Salmi et al (1) } & $3 D P-3 D C T$ & $0.67 \pm 0.43 \& 0.69 \pm 0.44$ \\
\hline & $S L S-3 D C T$ & $0.79 \pm 0.26 \& 0.80 \pm 0.32$ \\
\hline & PolyJet*-3D CT & $0.18 \pm 0.12 \& 0.18 \pm 0.13$ \\
\hline \multirow[t]{2}{*}{ El-Katatny et al (4) } & FDM - 3D CT skull & $0.24 \pm 0.16$ \\
\hline & FDM - 3D CT mandible & $0.22 \pm 0.11$ \\
\hline \multirow[t]{3}{*}{ Ibrahim et al (11) } & SLS - dry mandible & 1.79 \\
\hline & 3DP - dry mandible & 3.14 \\
\hline & PolyJet - dry mandible & 2.14 \\
\hline \multirow[t]{2}{*}{ Silva et al (7) } & SLS - dry skull & 2.10 \\
\hline & 3DP - dry skull & 2.67 \\
\hline Nizam et al (12) & SL - dry skull & $0.08 \pm 1.25$ \\
\hline Chang et al (6) & 3DP - fresh skull & $2.1-4.7$ \\
\hline Choi et al (5) & SL - dry skull & $0.56 \pm 0.39$ \\
\hline Asaumi et al (13) & $\mathrm{SL}$ - dry skull & 0.63 \\
\hline Berry et al (14) & $S L-3 D C T$ & 0.64 \\
\hline Barker et al (15) & SL - dry skull & $0.6-3.6$ \\
\hline Ono et al (16) & SL - dry skull & 3 \\
\hline
\end{tabular}

*Stratsys, USA. 3D Three-dimensional; 3DP 3D printing; CT Computed tomography; FDM Fused deposition modelling; ref Reference; SL Stereolithography; SLS Selective laser sintering

warping increases with model size (3). In our experience, ABS mandible models are particularly prone to warping and require a supporting strut to prevent narrowing of the mandibular width. The PLA mandible models in our study were very accurate without the use of a strut. 

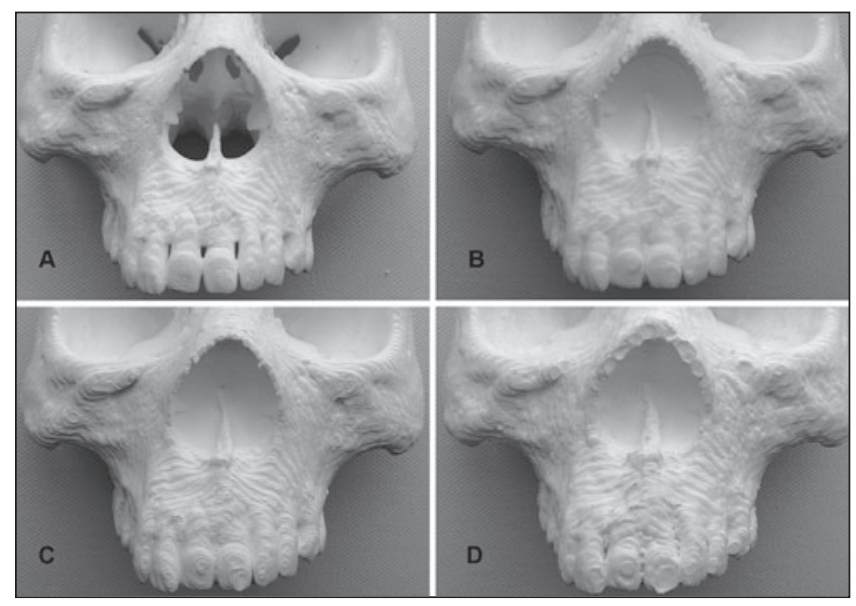

Figure 6) Comparison of midface models. A Selective laser sintering; B Fused deposition modelling (FDM) $100 \mu \mathrm{m}$; C FDM $250 \mu \mathrm{m}$; D FDM $500 \mu \mathrm{m}$

Reliable printing of surgical models is critical because reprinting failed models requires further investment of time and cost. Every PLA model in the present study was printed sequentially without any print failures. The warping associated with a consumer-grade FDM process using ABS plastic makes it less ideal for surgical models compared with PLA.

Support structures are necessary for printing FDM models with free floating or steeply inclined structures. Models should be oriented to decrease the number of support structures required because this reduces material use and print time significantly. Splitting a mandible model into two pieces eliminates the need for support structures entirely. Filling interior areas of a midface model speeds production by preventing printing of small and often poorly supported structures in the sinuses.

\section{REFERENCES}

1. Salmi M, Paloheimo KS, Tuomi J, Wolff J. Accuracy of medical models made by additive manufacturing (rapid manufacturing). J Craniomaxillofac Surg 2013;41:603-9.

2. Gibson I, Rosen DW, Stucker B. Commercial Machines. In: Additive Manufacturing Technologies: Rapid Prototyping to Direct Digital Manufacturing. New York: Springer, 2010:196-8.

3. Budmen I, Rotolo A. Fused filament fabrication. In: The Book On 3D Printing. Seattle: Createspace, 2013:22-8.

4. El-Katatny I, Masood SH, Morsi YS. Error analysis of FDM fabricated medical replicas. Rapid Prototyping Journal 2010;16:36-43.

5. Choi JY, Choi JH, Kim NK, et al. Analysis of errors in medical rapid prototyping models. Int J Oral Maxillofac Surg 2002;31:23-32.

6. Chang PS, Parker TH, Patrick Jr CW, Miller MJ. The accuracy of stereolithography in planning craniofacial bone replacement. J Craniofac Surg 2003;14:164-70.

7. Silva DN, Gerhardt de Oliveira M, Meurer E, Meurer MI, Lopes da Silva JV, Santa-Barbara A. Dimensional error in selective laser sintering and 3D-printing of models for craniomaxillary anatomy reconstruction. J Craniomaxillofac Surg 2008;36:443-9.

8. Huotilainen E, Paloheimo M, Salmi M, et al. Imaging requirements for medical applications of additive manufacturing. Acta Radiol 2014:55:78-85.

9. Athanasiou K, Niederauer G, Agrawal C. Sterilization, toxicity, biocompatibility and clinical applications of polylactic acid/ polyglycolic acid copolymers. Biomaterials 1998;17:93-102.

10. Massey LK. Acrylonitrile-Butadiene-Styrene (ABS). In: The Effects of Sterilization Methods on Plastics and Elastomers the Definitive User's Guide and Databook, 2nd edn. Norwich: William Andrew Publishers, 2005:19-38.

11. Ibrahim D, Broilo TL, Heitz C, et al. Dimensional error of selective laser sintering, three-dimensional printing and PolyJet models in the reproduction of mandibular anatomy. J Craniomaxillofac Surg 2009;37:167-73.
Limitations to the present study include testing only one FDM printer (there are currently dozens available with many combinations of hardware and software). These results, therefore, may not be generalizable to all low-cost FDM printers. Using a dry skull without soft tissues is the ideal situation for obtaining CT data and creating the 3D reconstruction. In clinical practice, the errors seen in the models would likely be greater due to obstruction from the soft tissues and patient movement. Future studies should examine other emerging consumer-grade 3D printing technologies based on STL using lasercured resin. These new technologies may offer additional increases in resolution and print speed, while maintaining a similarly low cost and ease of use.

The applicability of 3D printing extends beyond craniofacial surgery and has been used to plan complex hand surgeries, microtia reconstruction, custom designed implants and biological scaffolds for tissue engineering $(17-20)$. Increased access to $3 \mathrm{D}$ printing will help to drive innovation in this field, and it is likely that the full potential of this technology in plastic surgery has yet to be discovered.

\section{CONCLUSIONS}

Medical models produced on a consumer-grade FDM printer from CT image data have sufficient dimensional accuracy to be useful in maxillofacial operations. These printers offer a low-cost alternative for surgeons wanting to produce their own surgical models. FDM models with $100 \mu \mathrm{m}$ and $250 \mu \mathrm{m}$ layer height have similar accuracy, while the $250 \mu \mathrm{m}$ models take significantly less time to produce. Printing at a $250 \mu \mathrm{m} z$-axis resolution appears to best balance production time with accurate reproduction of the craniofacial skeleton.

ACKNOWLEDGEMENTS: The authors thank Andrew Goertzen for his help obtaining the skull CT data.

DISCLOSURES: The authors have no financial disclosures or conflicts of interest to declare.

12. Nizam A, Gopal RN, Naing L, Hakim AB, Samsudin AR. Dimensional accuracy of the skull models produced by rapid prototyping technology using stereolithography apparatus. Arch Orofac Sci 2006;1:60-6.

13. Asaumi J, Kawai N, Honda Y, Shigehara H, Wakasa T, Kishi K. Comparison of three-dimensional computed tomography with rapid prototype models in the management of coronoid hyperplasia. Dentomaxillofac Radiol 2001;30:330-5.

14. Berry E, Brown JM, Connell M, et al. Preliminary experience with medical applications of rapid prototyping by selective laser sintering. Med Eng Phys 1997;19:90-6.

15. Barker TM, Earwaker WJS, Lisle DA. Accuracy of stereolithographic models of human anatomy. Australas Radiol 1994;38:106-11.

16. Ono I, Gunji H, Suda K, Kaneko F. Method for preparing an exact size model using helical volume scan computed tomography. Plast Reconstr Surg 1994;93:1363-71.

17. Tan H, Yang K, Wei P, Zhang G, Dimitriou D, Xu L, Huang WA. Novel preoperative planning technique using a combination of CT angiography and three-dimensional printing for complex toe-tohand reconstruction. J Reconstr Microsurg 2015 March 18 (Epub ahead of print).

18. Rankin TM, Mailey B, Cucher D, Giovinco NA, Armstrong DG, Gosman A. Use of 3D printing for auricular template molds in first stage microtia. Plast Reconstr Surg 2014;134(4S-1):16-7.

19. Seitz H, Rieder W, Irsen S, Leukers B, Tille C. Three-dimensional printing of porous ceramic scaffolds for bone tissue engineering. J Biomed Mater Res B Appl Biomater 2005;74:782-8.

20. Zhim F, Ayers RA, Moore JJ, Moufarrège R, Yahia L. Personalized implant for high tibial opening wedge: Combination of solid freeform fabrication with combustion synthesis process. J Biomater Appl 2012;27:323-32. 